\title{
Sociocultural Input Facilitates Children's Developing Understanding of Extraordinary Minds
}

\author{
Jonathan D. Lane, Henry M. Wellman, and E. Margaret Evans \\ University of Michigan
}

\begin{abstract}
Three- to 5-year-old $(N=61)$ religiously schooled preschoolers received theory-of-mind $(\mathrm{ToM})$ tasks about the mental states of ordinary humans and agents with exceptional perceptual or mental capacities. Consistent with an anthropomorphism hypothesis, children beginning to appreciate limitations of human minds (e.g., ignorance) attributed those limits to God. Only 5-year-olds differentiated between humans' fallible minds and God's less fallible mind. Unlike secularly schooled children, religiously schooled 4-year-olds did appreciate another agent's less fallible mental abilities when instructed and reminded about those abilities. Among children who understood ordinary humans' mental fallibilities, knowledge of God predicted attributions of correct epistemic states to extraordinary agents. Results suggest that, at a certain point in ToM development, sociocultural input can facilitate an appreciation for extraordinary minds.
\end{abstract}

During the preschool years, children's understanding of the capacities and limitations of others' minds-their theory of mind (ToM) - undergoes rapid change (Harris, 2006; Wellman \& Liu, 2004). Two-year-olds appreciate that people hold desires, and that different people may desire different things (Repacholi \& Gopnik, 1997), and 3-year-olds additionally understand that people have thoughts and beliefs-mental representations of stimuli (e.g., objects, people) even in the physical absence of those stimuli (Wellman \& Estes, 1986). Shortly thereafter, children begin to appreciate certain limitations of the mind. For example, older 3-year-olds appreciate that people can be ignorant about something if they have not perceived it (Pratt \& Bryant, 1990). Most 5-year-olds additionally understand that people can hold false beliefs about the world based on inaccurate or outdated information (Perner, Leekam, \& Wimmer, 1987), and soon thereafter

Funding for this research was provided by National Institute of Child Health \& Human Development Grant HD022149 to Henry M. Wellman and by a Rackham School of Graduate Studies Research Grant to Jonathan D. Lane. We are very grateful to the children and parents who participated in this study and to the teachers and staff at the University of Michigan Children's Centers, Cornerstone Christian School, Go Like the Wind Montessori School, Lil' Saints Preschool, Livingston Christian School, and Our Father's Child Preschool. We also thank Jessie Emerick for her help coding children's open-ended responses. The manuscript benefited from suggestions provided by two anonymous reviewers on earlier drafts. Portions of this research were presented at the biennial meeting of the Cognitive Development Society, October 2009.

Correspondence concerning this article should be addressed to Jonathan D. Lane, Department of Psychology, University of Michigan, 530 Church St., Ann Arbor, MI 48109. Electronic mail may be sent to jonlane@umich.edu. children begin to appreciate that individuals have limited access to others' private beliefs (Miller, 2009). But children (and adults) are not confronted exclusively by ordinary human agents; people entertain beliefs about agents who possess extraordinary capacities that are distinctly nonhuman. For example, television shows and movies abound with characters who possess exceptional perceptual capacities (e.g., X-ray vision), and many of the world's religions espouse beings who possess extraordinary mental capacities (e.g., omniscience; Campbell, 1972/1993; Pickover, 2001). How do people come to understand the less constrained minds of these agents? In this article, we investigate the effects of sociocultural input and ToM on children's developing understanding of extraordinary minds.

In addition to providing a framework for how other people think and behave, a ToM can facilitate the representation of many sorts of minds, including the minds of nonhuman and superhuman beings (Boyer, 1996; Epley, Waytz, \& Cacioppo, 2007; Evans \& Wellman, 2006; Shtulman, 2008). Concepts of extraordinary perceptual and cognitive abilities begin to emerge during the preschool years. But there is disagreement as to when and how children differentiate between the minds of ordinary humans and the minds of extraordinary beings. Primarily, two theories have been proposed to account for young children's understanding of

(C) 2012 The Authors

Child Development (C) 2012 Society for Research in Child Development, Inc. All rights reserved. 0009-3920/2012/8303-0020

DOI: $10.1111 / j .1467-8624.2012 .01741 . x$ 
extraordinary minds. The first is an anthropomorphism hypothesis (Boyer, 1996; Piaget, 1929/1969), which states that children initially attribute to all agents the same psychological limits that they attribute to ordinary humans, and only later come to differentiate ordinary and extraordinary minds. Thus, for example, when children begin to appreciate that ordinary people can be ignorant or can hold false beliefs, they attribute the same cognitive limitation to all beings, ordinary and extraordinary. Before that time, children fail to understand the distinction between (potentially fallible) belief states and reality, so if required to judge beliefs they merely report states of reality for human and nonhuman agents. Several studies lend support to this theory (e.g., Giménez-Dasí, Guerrero, \& Harris, 2005). Using a knowledge-ignorance task, Makris and Pnevmatikos (2007) found that 3- and 4-yearolds reported that both a girl and God would be ignorant about the contents of a closed box without looking inside. Only children at age 5 and older differentiated between the girl's ignorance and God's correct knowledge of the box's contents.

However, other studies provide evidence that appears to counter the anthropomorphism hypothesis. Barrett and colleagues (e.g., Barrett, Richert, \& Driesenga, 2001; Knight, Sousa, Barrett, \& Atran, 2004), for example, administered false-belief and knowledge-access tasks to 3- to 7-year-olds, and found that the youngest children attributed "infallible" $^{\prime \prime}$ mental capacities (i.e., correct knowledge and correct beliefs) to all agents tested, including humans and God, and older children who attributed ignorance and false beliefs to humans (typically those 5 years and older) continued to attribute correct mental capacities to God. Barrett and colleagues conclude that these results support an alternative preparedness hypothesis (Barrett \& Richert, 2003), whereby children's early social-cognitive biases (e.g., not attributing false beliefs to agents) actually support the understanding of extraordinary mental abilities. That is, before children understand mental limitations (e.g., ignorance, error, or false beliefs), they do not merely use reality to attribute agents' mental states (per the anthropomorphism hypothesis); rather, they believe that agents are all knowing. Accordingly, when children begin to attribute a particular mental fallibility (e.g., false beliefs) to ordinary humans, they can simply continue to attribute infallible mental capacities and states to God.

These research findings apparently conflict and are thus difficult to integrate theoretically. Critically, most extant studies lack data that are key to testing the opposing hypotheses-namely, data on the specific types of capacities children are actually attributing to agents. Further, the prior studies typically group children in large age groups that may mask nuanced developmental trajectories. To address these issues, Lane, Wellman, and Evans (2010) asked children from secular schools to make judgments and reason about the knowledge and beliefs of agents with contrasting perceptual and mental abilities: ordinary humans; Heroman, who "can see right through things"; Mr. Smart, who "knows everything"; a cat with night vision; and a religious deity (God). Critical to sufficiently testing the preparedness and anthropomorphism hypotheses, they densely sampled children at an age when children were beginning to attribute ignorance and false beliefs to ordinary humans. Results indicated that the youngest children's (3-year-olds') attribution of correct knowledge and beliefs to all agents largely reflected a reality bias-when justifying their decisions, 3-year-olds referred to reality (specifically the box's current contents); they rarely mentioned the agents' mental capacities or constraints. Moreover, somewhat older children (essentially 4-year-olds) who were beginning to understand the mental limitations of ordinary agents (ignorance and fallible beliefs), attributed those same limitations to the minds of Mr. Smart and God. Only the oldest children (5 years and older) differentiated between the fallible mental capacities (and resulting knowledge and beliefs) of humans and the less constrained mental capacities and states of God and Mr. Smart. Intriguingly, the 4-year-olds did appreciate that some agents' exceptional perceptual abilities (e.g., Heroman's X-ray vision) could lead to accurate knowledge and beliefs, but they did not appreciate extraordinary mental abilities. Overall, these findings present clear evidence in support of the anthropomorphism hypothesis but also suggest that children come to appreciate some exceptional perceptual capacities (e.g., X-ray vision) before they appreciate extraordinary mental capacities (e.g., infallible beliefs).

One reason children may have an early appreciation of exceptional perceptual capacities is because perceptual capacities are observably more or less restricted across humans and animalssome people see well without glasses, others need them, dogs can hear silent dog whistles, and bats have echolocation that allows them to navigate in the dark. In addition, children's early grasp of exceptional perceptual abilities may reflect exposure to "testimony," and media in which characters possess special abilities (e.g., bat's 
echolocation, Superman's X-ray vision). Indeed, children may hear not only about exceptional perceptual abilities but also about extraordinary mental abilities through various forms of informal and formal sociocultural input (Bergstrom, Moehlmann, \& Boyer, 2006; Harris \& Koenig, 2006) - including broadly, parent-child discourse, oral and printed stories, movies, and formal or informal exposure to religious doctrine. Importantly, sociocultural input of these various forms can have powerful effects on children's conceptual development (Shweder et al., 2006), even if that information is not provided in an intentionally didactic manner (Atran \& Sperber, 1991). For example, a large body of research demonstrates predictive relations between everyday sociocultural input (e.g., parent-child discourse about mental states) and children's developing understanding of ordinary human minds (for a review, see Carpendale \& Lewis, 2004). Further, it is clear that sociocultural input affects older children's judgments of, for example, God's extraordinary ability to create the living world (Evans, 2001). However, surprisingly little is known about the effects of such input, and focally exposure to religious ideas, on children's developing concepts of extraordinary minds. It now seems unlikely that young children are cognitively prepared to understand extraordinary mental capacities, in that very young children evidence a reality bias, rather than an understanding of extraordinary mental capacities (Lane et al., 2010). Nonetheless, when children do begin to consider mental capacities of certain agents, exposure to certain religious doctrines may facilitate the acquisition and application of concepts of extraordinary mental capacities. In particular, children who are heavily exposed to ideas about agents with extraordinary cognitive abilities (e.g., doctrine about God's omniscience) may more easily resist attributing cognitive limitations (e.g., false beliefs) to such agents.

Many of the studies mentioned have included children from religious communities but, again, offer unclear or conflicting results. Makris and Pnevmatikos (2007) offer evidence in favor of the anthropomorphism hypothesis in a sample of Greek Orthodox children. Further, in a sample of Spanish children, Giménez-Dasí et al. (2005) found that only after age 5 did children attribute extraordinary abilities of God rather than the fallible mental abilities representative of humans, and this was true for religiously schooled as well as secularly schooled children. But Barrett et al. (2001) arguably found support for the preparedness hypothesis in a sam- ple of Christian children from the United States and in a sample of Yukatek Maya children (Knight et al., 2004).

To understand how these seemingly conflicting results may contribute to a unified theory of children's understanding of extraordinary minds, in the current study we addressed the interplay between sociocultural, religious input, and children's developing concepts of extraordinary minds in three ways: (a) we used the methods employed by Lane et al. (2010) with a sample of children who attended religious schools and who were knowledgeable about God, (b) we directly compared the religiously schooled children with the secularly schooled children from Lane et al. (2010), and (c) across both samples, we examined relations between children's knowledge of God and their understanding of extraordinary minds. To capture the potentially nuanced developmental trajectory of children's appreciation for extraordinary minds, we followed Lane et al. (2010) by densely sampling children in an age range when they were beginning to attribute particular mental fallibilities (ignorance and false beliefs) to ordinary humans, and asked children about the mental capacities of agents with contrasting abilities. These agents included ordinary humans, agents with exceptional perceptual capacities (a cat with night vision, and a superhero with X-ray vision), and agents with extraordinary mental capacities (Mr. Smart-an agent who "knows everything" — and God). We also systematically asked children to provide justifications for their decisions.

In advance, we can consider three possibilities. First, we might find results for religiously schooled children very similar to those found by Lane et al. (2010), who studied children from secular schools. In particular, when these religiously exposed children begin to appreciate a particular limitation of human minds (e.g., ignorance or false beliefs) they could, like secularly schooled children, initially attribute that same limitation to agents with extraordinary mental capacities (focally, agents purported to be all knowing). This would suggest that exposure to information about extraordinary minds does not affect young children's initial understanding of extraordinary mental capacities.

On the other hand, sociocultural input about extraordinary minds might facilitate an early ability to understand extraordinary mental capacities. Facilitation of children's understanding of extraordinary minds due to early religious exposure could manifest in either of two ways in the current study. One straightforward possibility is that young 
children who are knowledgeable about God will resist attributing ignorance or false beliefs to God at any point, even as they begin to attribute such mental fallibilities to ordinary humans. However, the effects of religious exposure and knowledge might be less straightforward and more subtle. For example, religiously exposed children may hear and accept information about God's extraordinary capacities, but those capacities may not loom large in their everyday thinking about God. Thus, a third possibility is that the influence of religious exposure may surface only when such children are explicitly informed and reminded about some agent's extraordinary abilities. Indeed, while even adult believers tend to think of God as subject to many human-like psychological constraints, they are less likely to do so if first asked questions (and so reminded) about the nature of God's powers (Barrett \& Keil, 1996).

Children's open-ended justifications for the ToM tasks could also shed light on the nature and timing of any facilitation due to religious exposure. For example, possible facilitation effects could potentially occur very early, even before children begin to appreciate limits of ordinary minds. In this case, very young religiously exposed children should mention agents' special mental abilities (rather than merely reference reality) in their justifications. Alternatively, children may only begin to mention extraordinary capacities after they appreciate certain ordinary limits of human minds (e.g., false beliefs or ignorance).

\section{Method}

\section{Participants}

Sixty-four children participated, all of whom attended religious Protestant Christian preschools; they were primarily of European American descent and middle-class socioeconomic status. We densely sampled in an age range (54-59 months) in which, pilot testing showed, children were particularly likely to begin attributing ignorance or false beliefs to ordinary humans. The data from 3 children who were notably distracted were excluded, leaving 61 children (27 males) in the final sample, ranging in age from 37.87 to 76.53 months $(M$ age $=56.92$ months).

Children were recruited from Christian schools (all of which mentioned God and/or Christ in their mission statements); these institutions provide a pool of participants who are typically exposed to religion, at least at school. School affiliation is the most commonly used method employed in prior research to recruit religiously exposed children (e.g., Bering, Hernández Blasi, \& Bjorklund, 2005; Giménez-Dasí et al., 2005; Richert \& Barrett, 2005). However, because parents undoubtedly vary in their reasons for having their children attend religious schools, we sought additional information as to children's religious exposure and knowledge. In particular, we asked children about God at several points in our procedures. From these data (see Results) we found that $87 \%$ were familiar with God, and that $79 \%$ were able to provide specific details about God (e.g., "God made us"; "God knows everything"). Thus, our sample was not only religiously exposed; children remembered key details about God. To gather additional information on children's religious exposure, we distributed a follow-up questionnaire to all of the children's parents. Thirty-eight parents (parents of $62 \%$ of the children) returned the questionnaire. Parallel to the proportion of children who were familiar with the concept of God, $84 \%$ of these parents reported that their children attend a place of worship, most on a weekly basis.

\section{Procedure}

Children were interviewed individually at school, using two tasks identical to those employed by Lane et al. (2010): a contents false-belief task (Perner et al., 1987) and a knowledge-ignorance task similar to that used by Barrett et al. (2001). Half of the children received the knowledge-ignorance task first; the others received the false-belief task first. Children were introduced to each agent (displayed on a card) upon their first exposure to that agent (for images of the agents and details on how each agent was introduced, see the Appendix). For each task, children were presented the girl first; the remaining agents were presented in random order (except mom was never presented following the girl).

\section{Measures}

False-belief understanding. Children were shown a crayon box and paper bag. The interviewer asked children what they thought was inside the crayon box and then opened both containers to reveal that the box held marbles and the paper bag held crayons. Both containers were then closed and the interviewer checked if children remembered the contents of both containers; corrective feedback was offered when necessary but was rarely required. Then, for each of five agents, children were asked: 
" has never been in the room with these things before. If we show - this box, all closed up, [pictured agent approaches crayon box] what will think is inside here?" Children were asked this question with regard to a girl, their mother, $\mathrm{Mr}$. Smart (a man who, children were instructed, "knows everything"), Heroman (a superhero with X-ray vision), and God (no information was given about God). Importantly, the example that we provided to children in Mr. Smart's introduction (his knowing the contents of a box without looking inside) is directly applicable to our social-cognitive tasks, for which children decide whether agents know the contents of containers. To assess the effects of anthropomorphic cues on children's concepts of God, half of the sample was not shown a picture representing God and were not told that God had "never been in the room"; they were just asked "What will God think is inside here?" To assess children's understanding of Mr. Smart's allknowing abilities (without reliance on visual abilities), children were asked what Mr. Smart would think is in the box if he was far from the box facing in the opposite direction. For each agent, children earned a score of 0 if they ascribed a correct belief or 1 if they ascribed a false belief. Following each judgment, the interviewer prompted children to justify their answer by asking, "Why will _ think _ are inside?"

Knowledge-ignorance understanding. Children were shown two boxes that each had a slit, allowing visual access. Above the first box, a lamp was turned on, illuminating the inside of the box and revealing a red plastic frog inside. Above the second box, a lamp was turned off, and that box appeared empty. Children looked into each box and reported what they saw. After children affirmed that the lit box contained a frog and that they could see nothing in the unlit box, the experimenter turned on the lamp above the previously unlit box, revealing another red frog inside. That light was then turned off, and the experimenter reminded children, "So, both boxes have a frog inside but you can't see the frog when this one is dark [pointing at the unlit box]." The interviewer then checked if children remembered the contents of both boxes; corrective feedback was offered when needed but was rarely required. Children were then asked the following for each of six agents with regard to the unlit box: " _ has never been in this room with these boxes before. If _ comes very close to the top of the dark box, what will _ think is inside here; a frog or nothing?" For this focal question, the experimenter held the agent's picture above the unlit box, facing the contents of the box. Children were asked this question for each of six different agents: a girl, their mom, Mr. Smart (a man who "knows everything"), Heroman (a superhero with X-ray vision), and God (about whom children were told nothing). Because this knowledge-ignorance task involves specifically children's understand that darkness limits visual access to information, we added another agent with perceptual abilities that were directly applicable to this task-a cat that can see in the dark (see also Barrett et al., 2001; Lane et al., 2010). Again, half of the sample received no picture of God and were not told that God had "never been in this room"; they were only asked "What will God think is inside here; a frog or nothing?" To emphasize Mr. Smart's reliance on mental and not visual abilities, children were asked what Mr. Smart would think is in the box if he was far from the box, facing away from the box. For each agent, children earned a score of 0 if they attributed correct knowledge or 1 if they attributed ignorance. Following each judgment, the interviewer prompted children to justify their answer by asking, "Why will _ think _ is inside?" Children's understanding of ignorance can be measured with a variety of tasks. We chose this task because it parallels that used by Barrett et al. (2001) and is identical to the one used by Lane et al. (2010), thus allowing a direct comparison with their findings. As is typical with knowledge-ignorance tasks (Wellman \& Liu, 2004), Lane et al. (2010) found that children pass this task earlier than the false-belief task.

Knowledge of God. To obtain further information about children's knowledge of God, following the ToM tasks, the interviewer told children, "Tell me about God." If children could not provide any details initially, they were prompted, "Tell me anything you know about God." If children still provided no information, children were asked, "Have you ever heard of God?"

Coding. The reasoning children used to justify their knowledge-ignorance and false-belief judgments were coded into 10 focal categories (see Table 1) and an additional "uninformative" category. To assess interrater reliability, $25 \%$ of the justifications were coded by two coders (one blind to all hypotheses of the study); all $\kappa s \geq .88$.

Children's familiarity with information about God was assessed using their justifications for God's knowledge and beliefs for the ToM tasks combined with children's responses to the final open-ended questions about God. Knowledge of God was coded as an ordinal variable with higher 
Table 1

Coding of Open-Ended Responses

\begin{tabular}{|c|c|c|c|}
\hline \multirow[b]{2}{*}{ Category } & \multirow[b]{2}{*}{ Description } & \multicolumn{2}{|c|}{ Examples } \\
\hline & & Knowledge-ignorance task & False-belief task \\
\hline Reality based & $\begin{array}{l}\text { Cites actual contents of container } \\
\text { without mentioning agent's } \\
\text { mental or perceptual capacities }\end{array}$ & $\begin{array}{l}\text { "There is a frog" } \\
\text { "Someone put it in there" }\end{array}$ & $\begin{array}{l}\text { "There are marbles inside the } \\
\text { box" } \\
\text { "The crayons are in the bag" }\end{array}$ \\
\hline Appearance based & Cites the appearance of the box & $\begin{array}{l}\text { "It's dark" } \\
\text { "It's very dark" }\end{array}$ & $\begin{array}{l}\text { "It has crayons on it" } \\
\text { "There's a sign with crayons" }\end{array}$ \\
\hline Typicality based & $\begin{array}{l}\text { Cites the type of container or } \\
\text { mentions what that type of } \\
\text { container typically holds }\end{array}$ & $\begin{array}{l}\text { "It's supposed to be in there" } \\
\text { "It belongs in there" }\end{array}$ & $\begin{array}{l}\text { "It's a crayon box" } \\
\text { "They belong in there" }\end{array}$ \\
\hline $\begin{array}{l}\text { Inadequate } \\
\text { perceptual } \\
\text { capacities }\end{array}$ & $\begin{array}{l}\text { Cites agent's inadequate, senses } \\
\text { (e.g., inadequate vision) }\end{array}$ & $\begin{array}{l}\text { "It's too dark to see inside" } \\
\text { "He can't see all the way } \\
\text { down" }\end{array}$ & $\begin{array}{l}\text { "She can't see what's inside" } \\
\text { "Someone can't see there" } \\
\text { "He's not here" }\end{array}$ \\
\hline $\begin{array}{l}\text { Exceptional } \\
\text { perceptual } \\
\text { capacities }\end{array}$ & $\begin{array}{l}\text { Cites agent's exceptional senses } \\
\text { (e.g., vision, hearing) }\end{array}$ & $\begin{array}{l}\text { "He can see in the dark" } \\
\text { "He can see through } \\
\text { everything" }\end{array}$ & $\begin{array}{l}\text { "He can see through the box" } \\
\text { "He can look through stuff" }\end{array}$ \\
\hline $\begin{array}{l}\text { Extraordinary } \\
\text { mental capacities }\end{array}$ & $\begin{array}{l}\text { Cites agent's mental capacities } \\
\text { without referring to perceptual } \\
\text { capacities }\end{array}$ & $\begin{array}{l}\text { "He's very smart" } \\
\text { "He's a good rememberer" }\end{array}$ & $\begin{array}{l}\text { "He's super smart" } \\
\text { "He knows a lot" }\end{array}$ \\
\hline $\begin{array}{l}\text { Adequate } \\
\text { perceptual or } \\
\text { mental capacities }\end{array}$ & $\begin{array}{l}\text { Explains that the agent will } \\
\text { perceive or know the contents of } \\
\text { container without referencing } \\
\text { extraordinary abilities }\end{array}$ & $\begin{array}{l}\text { "Because he saw it" } \\
\text { "He'll see a frog" } \\
\text { "She knows a frog's in there" }\end{array}$ & $\begin{array}{l}\text { "He'll see marbles" } \\
\text { "She looked in there" } \\
\text { "Because she knows" }\end{array}$ \\
\hline Powerful & $\begin{array}{l}\text { Cites the agent's general } \\
\text { powerfulness without referencing } \\
\text { specific perceptual or mental } \\
\text { abilities }\end{array}$ & $\begin{array}{l}\text { "He has every kind of powers" } \\
\text { "He has lots of power" }\end{array}$ & $\begin{array}{l}\text { "He's powerful and he's great" } \\
\text { "He has powers" }\end{array}$ \\
\hline Creator & $\begin{array}{l}\text { Reports that the agent designed or } \\
\text { created the focal stimuli }\end{array}$ & "He made animals" & $\begin{array}{l}\text { "He made marbles" } \\
\text { "He made them and put them } \\
\text { in the crayon box; and he } \\
\text { made the box" }\end{array}$ \\
\hline Want/Desire based & $\begin{array}{l}\text { Explains how agent's knowledge } \\
\text { or beliefs were driven by desires } \\
\text { or preferences }\end{array}$ & $\begin{array}{l}\text { "He wanted to play with it" } \\
\text { "He wants to give it to another } \\
\text { person for a pet" }\end{array}$ & $\begin{array}{l}\text { "She likes marbles" } \\
\text { "Boys love to play with toys" } \\
\text { "She wants to play with them" }\end{array}$ \\
\hline
\end{tabular}

values representing greater knowledge of God, especially God's extraordinary powers: (0) Child does not report knowing about God, (1) child has heard of God but cannot provide details, (2) child provides some details about God (e.g., location, physical status, role, relevance in prayer, connection with Jesus, connection with Heaven; mentions that God is "loving," "not a person," "a special person"), (3) child mentions exceptional abilities that are not perceptual or mental (e.g., role in creation, omnipresence, "God has powers"), or (4) child specifically mentions extraordinary perceptual or mental abilities. Similar measures (aggregating across multiple responses) have been used effectively in other studies investigating relations between children's religious knowledge and conceptual development (e.g., Bamford \& Lagattuta, 2010). Intercoder agreement was $96.7 \%$ for the current knowledge of God measure.

\section{Results}

In preliminary analyses, we assessed whether the presentation of the image representing God and language suggesting God's physical presence affected 
children's attribution of anthropomorphic, fallible mental abilities to God. For the false-belief task, $27 \%$ of children who were presented the image and language, and $16 \%$ of those children who neither saw the image nor heard the language, attributed to God a false belief, $\chi^{2}(1, N=61)=1.01$, ns. For the knowledge-ignorance task, $47 \%$ of children who were presented the image and language, and 19\% who neither saw the image nor heard the language, attributed ignorance to God, $\chi^{2}(1, N=61)=5.16$, $p=.023$. Because this one effect of image did not vary between age groups-i.e., in a 3 (age group) $\times$ 2 (image + language vs. no image + language) analysis of variance (ANOVA) there was no interaction between age and image, $F(2,55)=.35, n s$, $\eta_{p}{ }^{2}=.01$ - and because of modest sample sizes, we combined both groups of children in our main analyses.

In the following analyses, "correct knowledge" and "correct beliefs" refer to judgments that an agent knows what is actually in the boxes (for the false-belief task, marbles; for the knowledgeignorance task, a frog). "Ignorance" and "false beliefs" refer to judgments that an agent is mistaken about the contents of the boxes (for the knowledge-ignorance task, that the agent thinks nothing is inside; for the false-belief task, that the agent thinks crayons are inside). Initial analyses assessed whether some children concurrently attributed human-like, fallible mental states to normal humans and to extraordinary beings, as expected under an anthropomorphism hypothesis. Indeed, many children attributed ignorance or false beliefs to each of the special agents-God, Mr. Smart, and Heroman-and those who did so also attributed false beliefs and ignorance to the girl and mom at levels above chance-God, $\chi^{2} \mathrm{~s}(1)$ $>9.30, p \mathrm{~s}<.01$; Mr. Smart, $\chi^{2} \mathrm{~s}(1)>9.30$, ps < .01; Heroman, $\chi^{2} \mathrm{~s}(1)>3.50, \quad p s<.06$. Thus, many children consistently attributed limited mental capacities to all agents.

Of focal interest was whether a pattern of attributing human-like capacities to "special" agents would be common when children began to understand that humans may hold fallible mental states. Thus, initially, we examined children's judgments to find developmental periods during which children first began attributing ignorance and false beliefs, respectively, to ordinary humans (their mom and the girl)-constitution of the "middle" age groups for both tasks were based on these data, their judgments of ordinary humans. For the oldest age groups, we identified immediately subsequent periods during which children consistently attrib- uted accurate knowledge or beliefs, respectively, to God. Because children often reach an understanding of ignorance and false-beliefs at different points in ToM development (Wellman \& Liu, 2004), it was important to create separate age groupings for the knowledge-ignorance task and false belief task. Based upon this preliminary analysis, we divided children into three age groups for the knowledgeignorance task: 15 in the young group (37.951.0 months; $M=45.6), 20$ in the middle group (51.2-59.6 months; $M=55.9$ ), and 26 in the oldest group (59.7-76.5 months; $M=64.2$ ); and for the false-belief task: 23 in the young group (37.955.4 months; $M=48.3$ ), 12 in the middle group (55.6-59.7 months; $M=57.7$ ), and 26 in the oldest group (59.7-76.5 months; $M=64.2$ ). Thus, the middle age group for the knowledge-ignorance task is younger than the middle age group for the falsebelief task (consistent with the meta-analysis of Wellman \& Liu, 2004, as well as the findings of Lane et al., 2010).

\section{Judgments}

Figures 1 and 2 depict the percentage of children who attributed ignorance and false beliefs to each agent, by age group. An initial repeated measures ANOVA for children's attributions of ignorance with age as a between-subjects factor (3: young, middle, old), and agent as a within-subjects factor (6: mom, girl, Mr. Smart, Heroman, cat, God), revealed significant main effects for age, $F(2,58)$ 9.66, $p<.001, \eta_{p}^{2}=.25$, and agent, $F(5,54)=$ $10.43, p<.001, \eta_{p}{ }^{2}=.49$, and a significant interaction between age and agent, $F(10,108)=2.16, p<.05$, $\eta_{p}{ }^{2}=.17$. A separate ANOVA assessing children's attributions of false beliefs to the five agents (the cat was not included in the false-belief tasks) revealed similar effects of age, $F(2,58)=10.48, p<.001$, $\eta_{p}{ }^{2}=.27$, and agent, $F(4,55)=11.63, p<.001$, $\eta_{p}^{2}=.46$, and a significant interaction between age and agent, $F(8,110)=3.23, p<.01, \eta_{p}^{2}=.19$.

These interactions were explored in individual, repeated measures ANOVAs for each age group, revealing that for the youngest children there were no differences between agents in children's attributions of ignorance, $F(5,10)=1.63, n s, \eta_{p}{ }^{2}=.20$, or false beliefs, $F(4,19)=1.26, n s, \eta_{p}{ }^{2}=.16$; young children attributed correct mental states to all agents at levels significantly greater than chance ( $t \mathrm{~s}>2.80, p s<.05$ ). Compared to the youngest children, those in the middle age groups attributed ignorance more often to the girl, mom, God, and Mr. Smart, ts(33) > 2.03, ps < .05, Cohen's ds $>0.70$, 


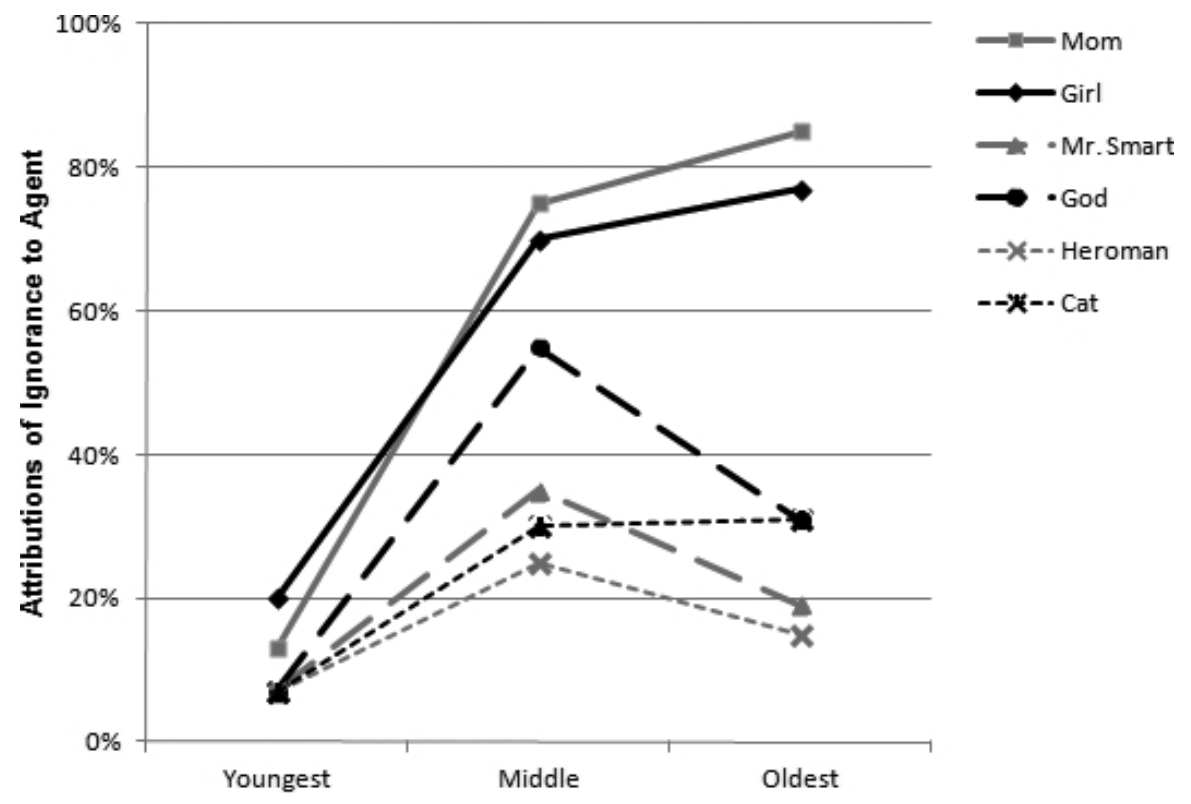

Figure 1. Percentage of children, by age group, reporting that the agent will be ignorant about the contents of the unlit box (i.e., will think that the unlit box has nothing inside).

and attributed false beliefs more often to the girl, mom, and God, ts $(33)>3.03$, ps $<.01$, Cohen's $d s>0.95$. There were, however, no differences between the youngest and middle groups in attributions of correct mental states (i.e., the containers' actual contents) to the agents with exceptional perception-Heroman and the cat.

Within the middle age groups, children selectively attributed ignorance, $F(5,15)=3.13, p<.05$, $\eta_{p}^{2}=.51$, and false beliefs, $F(4,8)=3.29, p=.07$, $\eta_{p}^{2}=.62$, to the different agents, as did children in the oldest age groups for the knowledge-ignorance task, $F(5,21)=13.05, p<.001, \eta_{p}{ }^{2}=.76$, and the false-belief task, $F(4,22)=8.67, p<.001$, $\eta_{p}{ }^{2}=.61$. Specifically, children in the middle groups differentiated between the correct mental states of Heroman and the cat, and the fallible mental states of ordinary humans (mom and the girl), for knowledge, $t s(19)>2.90, \quad p s<.01$, Cohen's ds $>1.30$; for beliefs ts $(11)>2.34, p s<.05$, Cohen's $d s>1.40$. But children in the middle groups generally did not differentiate between the mental states of the ordinary humans (mom and the girl) and the mental states of God (to whom more than half of the children attributed ignorance or false beliefs). Across multiple comparisons between God and the ordinary humans, just one-mom versus God for the false-belief taskwas significant, $t(11)=2.35, p<.05, \quad$ Cohen's $d=1.41$. Only the oldest children (59 months and older) consistently differentiated between the correct knowledge and beliefs of God and the fallible knowledge and beliefs of mom and the girl, ts $(25)>4.04, p s<.001$, Cohen's $d s>1.60$. In these respects, our data mimic those of Lane et al. (2010). In contrast to those data on children from nonreligious schools, however, these religiously schooled children in both middle and older groups attributed correct knowledge and beliefs to Mr. Smart, unlike mom and the girl, ts $>2.66$, ps $<.05$, Cohen's $d \mathrm{~s}>1.50$.

Parametric statistics were used in these focal analyses because ANOVAs are robust against violations of assumptions of normality for such data, and indeed may be preferable in repeated measures designs using dichotomous data (Seeger \& Gabrielsson, 1968). Nonparametric results further confirm our core findings. In these analyses, the overall effects for agent remained significant for knowledge-ignorance judgments (Cochran's Q = 78.61, $p<.001)$, and for false-belief judgments (Cochran's $Q=60.15, p<.001$ ). Significant differences in judgments of ignorance and false beliefs between the youngest and middle age groups were replicated using Mann-Whitney $U$ tests ( $U s \leq$ $107.50, \mathrm{Zs} \geq 1.95$, $p \mathrm{~s} \leq .05$ ). And within age group differences in children's attributions of ignorance or false beliefs to pairs of agents (e.g., mom vs. Mr. Smart) were replicated using Wilcoxon signed ranks tests $(Z s \geq 2.00, p s<.05)$. 


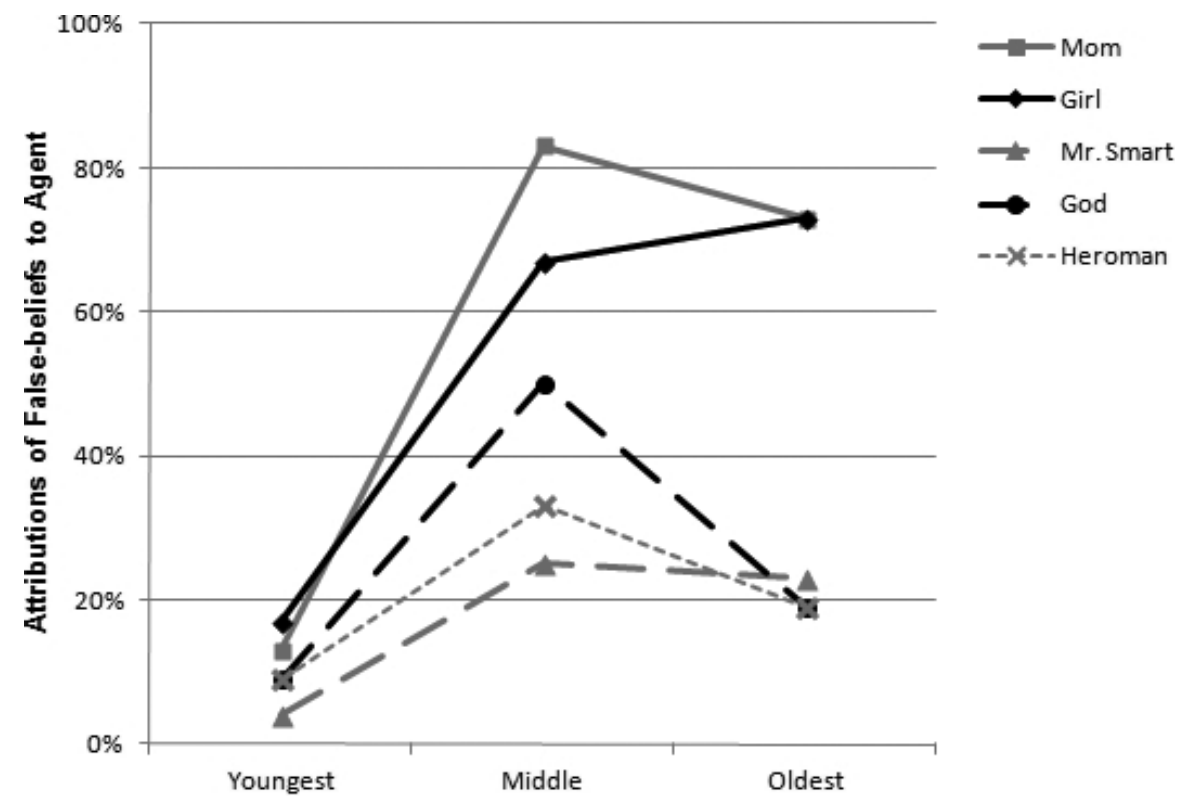

Figure 2. Percentage of children, by age group, reporting that the agent will hold a false belief (i.e., will think that there are crayons in the box).

\section{Justifications}

Children's justifications clarify the reasoning used in making their judgments. We focus on three contrasting "special" agents: Heroman (whose special vision was described), Mr. Smart (who was described as having an extraordinary mind, but no specific exceptional perceptual mechanism), and God (about whom we told children nothing). Justifications for correct knowledge and beliefs are particularly revealing because they address which (if any) extraordinary capacities children attributed to these agents. Table 2 presents data on the primary ways in which children justified these three agents' correct knowledge and beliefs. The column with the mean ages depicts an age-graded trend in children's justifications: at younger ages, children cited reality (e.g., "There are marbles inside the box," "There is a frog") or provided uninformative answers (e.g., "Because," "I don't know"), at a somewhat older age children cited agents' adequate perceptual or mental capacities (e.g., "He saw it," "She knows"), and at the oldest ages children made specific reference to agents' exceptional perceptual or extraordinary mental abilities (e.g., "He can see through the box," "He's super smart").

Children could offer different types of justifications for each of the three "special" agents, and so to assess whether these age trends were statistically significant, we split children into two independent groups for both of the tasks: (a) those children who referred to reality or provided uninformative answers (and who never cited exceptional/extraordinary mental or perceptual capacities) and (b)

Table 2

Justifications Used to Explain Agents' Correct Knowledge and Beliefs

\begin{tabular}{|c|c|c|c|c|c|c|}
\hline \multirow[b]{2}{*}{ Category } & \multicolumn{3}{|c|}{ Correct knowledge } & \multicolumn{3}{|c|}{ Correct beliefs } \\
\hline & $M$ age & SE & $n$ & $M$ age & SE & $n$ \\
\hline Uninformative & 51.43 & 2.53 & 14 & 52.12 & 2.14 & 17 \\
\hline Reality & 52.70 & 2.51 & 8 & 52.53 & 2.04 & 14 \\
\hline Adequate perception or adequate mental & 56.83 & 3.05 & 10 & 58.02 & 3.60 & 8 \\
\hline Exceptional perception & 60.80 & 1.03 & 27 & 60.87 & 1.28 & 26 \\
\hline Extraordinary mental & 60.54 & 1.24 & 24 & 60.79 & 1.21 & 25 \\
\hline
\end{tabular}

Note. $n=$ number of children who used justification category at least once to account for the correct knowledge or beliefs of Heroman, Mr. Smart, or God. 
those children who cited exceptional/extraordinary mental or perceptual capacities (and who never cited reality or provided uninformative answers). For the false-belief task, $85 \%$ of the children fell into one of the two groups, and children who provided uninformative or reality-based justifications were significantly younger $(M$ age $=50.02, S D=7.39)$ than children who cited extraordinary mental or perceptual abilities ( $M$ age $=60.62, S D=6.49$ ), $t(50)=5.49, p<.001$, Cohen's $d=1.52$. For the knowledge-ignorance task, $80 \%$ of the children fit into one of the two groups, and children who cited reality or provided uninformative answers were again significantly younger $(M$ age $=51.51$, $S D=8.97)$ than children who explicitly cited extraordinary mental or perceptual capacities $(M$ age $=$ 60.45, $S D=5.63), \quad t(47)=4.30, p<.001$, Cohen's $d=1.19$. Thus, although the youngest and oldest groups of children both attributed "correct" mental states to the special agents, they evidenced very different reasoning, with the youngest children displaying a reality bias and the oldest children demonstrating an appreciation for the agents' particular mental and perceptual powers.

\section{Religiously Schooled Versus Secularly Schooled Children}

The tasks and procedures used here are identical to those used by Lane et al. (2010) for 56 children attending secular preschools (ages 40-73 months; $M$ age $=54$ months). Across both samples, 77 parents $(66 \%)$ completed a questionnaire on their children's religious exposure-38 parents $(62 \%)$ for the current religiously schooled sample, and 39 parents (70\%) for Lane et al.'s secularly schooled sample. Using a scale from 1 (never) to 5 (daily), those parents in the current religiously schooled sample reported that their children were exposed to significantly more media (stories, movies, music, games) about $\operatorname{God}(M=3.29, S D=0.93)$ than did parents of secularly schooled children from Lane et al. $(M=1.99, S D=0.96), t(75)=6.07, p<.001$, Cohen's $d=1.37$. Moreover, parents of the religiously schooled children reported that their children more frequently attended a place of worship $(M=3.45$, $S D=1.03$ ) than the secularly schooled children from Lane et al. $(M=2.26, S D=1.35), t(75)=4.34$, $p<.001$, Cohen's $d=0.99$.

These parental data help confirm that school attended (religious vs. secular) was a reliable proxy for children's overall exposure to concepts of God. Moreover, the identical procedures used in the two studies allow some informative comparisons based on religious exposure. Comparisons across all con- ditions for the two groups of children (religious vs. secularly schooled) would be problematic because the children came from different communities and the age ranges indentified for the critical "middle age" children are different for the religiously and secularly schooled groups. Nonetheless, several focal comparisons are possible. In particular, while trends and results are largely parallel in both studies for most agents, there are some key differences, especially for Mr. Smart. First, using the same age range for the middle group as that used by Lane et al. (2010; for knowledge-ignorance: 49.554.5 months; for false belief: 52.5-58.9 months), religiously schooled children in this middle age group attributed correct mental states (knowledge and beliefs of the containers' actual contents) to Mr. Smart (but not God) significantly above chance: $\chi^{2}(1, n=9)=5.44, p<.05$ for knowledge; $\chi^{2}(1$, $n=14)=7.14, p<.01$ for beliefs; whereas similarly aged secularly schooled children attributed fallible mental states to Mr. Smart, just as they did for mom, the girl, and God. Further, religiously schooled children in this age range were much more likely to attribute correct knowledge and beliefs to Mr. Smart (Mann-Whitney Us $<60.00$, $\mathrm{Zs}>2.78, \quad p s<.01)$ than were their secularly schooled peers. They were also somewhat more likely to attribute correct knowledge and beliefs to God (Mann-Whitney Us $<77.00, \quad Z s>1.97$, $p s<.05)$.

Beyond using school as a proxy for religious exposure, we also more directly gauged children's religious exposure by their scores on our knowledge of God measure. These data, yielding a score of 0-4 summarizing children's knowledge of God, were available for every child in both studies $(n=117)$. On this knowledge of God measure, religiously schooled children in the current study scored significantly higher $(M=2.56, S D=1.38)$ than secularly schooled children in Lane et al. (2010; $M=1.88, S D=1.67), t(115)=2.41, p<.05$, Cohen's $d=0.44$. Of the religiously schooled children, $79 \%$ received scores $>1$ (provided details about God), and 56\% received scores of 3 or 4 (mentioned God's exceptional abilities). In contrast, only $59 \%$ of the secularly schooled children from Lane et al. received a score of 1 or greater and only $37 \%$ received scores of 3 or 4 .

Children's knowledge of God not only further validates the group differences in religious exposure, it provides an additional way to consider how exposure to religious instruction influenced children's responses on our tasks. Collapsing across data from both the religious and secular samples, 
we assessed the relation between children's knowledge of God and their attributions of ignorance and false beliefs to three of the "special" agents: God, Mr. Smart, and Heroman. For both tasks, Pearson correlations indicated that children's knowledge of God predicted their attributions of correct mental states to the three agents, but only among children who understood the constraints of human minds (i.e., who attributed ignorance or false beliefs, respectively, to both the girl and mom). Thus, for children who attributed false beliefs to Mom and the girl, knowledge of God predicted attributions of correct beliefs to God, $r(55)=.50, p<.001$; to Mr. Smart, $r(55)=.35, p<.01$; and to Heroman, $r(55)=.45, p<.001$. Similarly, among children who attributed ignorance to Mom and the girl, knowledge of God predicted attributions of correct knowledge to God, $r(65)=.45, p<.001$, and Heroman, $r(65)=.24, p=.05$; for Mr. Smart the trend was in the expected direction, albeit nonsignificant, $r(65)=.20$.

We next assessed relations between children's knowledge of God and the justifications they offered when considering the mental states of the other two special agents, Heroman and Mr. Smart. For each of the five most often used categories-extraordinary mental abilities, exceptional perception, adequate abilities, reality-based reasoning, and uninformative reasoning-children were given a point if they used that justification for either Heroman or Mr. Smart on the false-belief task, and a point if they used that justification for either agent on the knowledge-ignorance task (scores for each of the five justification categories could range from 0 to 2). Controlling for age, children's knowledge of God predicted less use of uninformative justifications, $r(114)=-.19, p<.05$; marginally fewer references to adequate abilities, $r(114)=-.16, p=.09$; and focally, greater reference to exceptional perception, $r(114)=.24, p<.01$, as well as extraordinary mental abilities, $r(114)=.25$, $p<.01$. In sum, more sophisticated knowledge of God's abilities predicted greater reference to exceptional or extraordinary capacities for other special agents, and this was not merely a function of other age-related developments.

\section{Discussion}

Human social cognition is characterized by an ability to consider the ordinary minds of fellow humans as well as the extraordinary minds of nonhuman and superhuman beings (Boyer, 1996).
Several recent studies suggest that the route through which children come to appreciate such extraordinary minds is best described as anthropomorphic. Initially, very young children treat all minds similarly in that they fail to understand the distinction between (potentially fallible) mental states and reality. Thus, on standard ToM tasks, if required to judge others' knowledge or beliefs they merely report states of reality for ordinary humans and for extraordinary agents. Second, and critically, when children begin to appreciate certain limitations of human epistemic states (e.g., false beliefs) they attribute those same cognitive constraints to most other agents, including supernatural agents (Giménez-Dasí et al., 2005; Lane et al., 2010; Makris \& Pnevmatikos, 2007). The current study revealed this overall pattern of results from children who were raised in specifically religious contexts and who were knowledgeable about God, using methods that help to resolve discrepancies in prior results. The detailed findings go beyond confirming an early childhood anthropomorphism, however, to shed light on ways in which sociocultural input about agents with supernatural mental capacities (i.e., exposure to knowledge about God) influences an early appreciation for extraordinary mental abilities.

A strict anthropomorphism account would claim that young children think of God (and all other special agents) in terms of human capacities and do so throughout the preschool years and well beyond (Piaget, 1929/1969). Much recent data, including our own, contradict any such strict account by demonstrating that 4- and 5-year-olds often allow some agents certain nonhuman capacities, as is first apparent for exceptional perceptual capacities (our Heroman and cat, but see also Richert \& Barrett, 2005). As we have noted, however, one key issue concerns children at transitional points when they are beginning to acknowledge particular limits of human mental capacities. Although they espouse preparedness rather than anthropomorphism, Richert and Barrett (2005) also adopt this view when they say that, if the anthropomorphism account is correct, then "when children understand that humans have limited perspectives, they will also attribute limited perspectives to God and other nonhumans . . . a 3-year-old's apparently accurate representation of God will begin to disintegrate as he or she acquires a "theory of mind"' (p. 292). The current study, along with others (Giménez-Dasí et al., 2005; Lane et al., 2010; Makris \& Pnevmatikos, 2007), lends support to just such an anthropomorphism hypothesis. 
Our evidence from children's justifications reveals that, much like secularly schooled children (Lane et al., 2010), young religiously schooled children's failure on false-belief and knowledgeignorance tasks reflects an early reality bias, not an appreciation for extraordinary mental abilities. That is, very young children simply reference conditions in the world, reality, to infer others' mental states, without considering others' mental limits (like false beliefs) or mental capacities (like omniscience). Further, the current data demonstrate that much like children from secular schools, religiously schooled children who are beginning to appreciate certain limitations of human minds (ignorance and false beliefs) typically also attribute those constraints to agents whom they are raised to believe "know everything" - in this case, the Judeo-Christian God. We focus on God here, for the moment, because Barrett and colleagues in articulating their preparedness account claim that children should always "resist treating God like a human." Further, they claim that it is "quite easy for young children to represent God as different from humans" (Richert \& Barrett, 2005, pp. 292-293). On the contrary, with regard to God in particular, data from the current study provide compelling evidence that when children begin to understand the cognitive limitations of humans, they typically attribute those same limitations to God, and this applies even to religiously exposed children. Only later, at around age 5 years did religiously exposed children reliably differentiate between humans' fallible mental abilities and inaccurate mental states versus God's less fallible abilities and states. These results suggest that in their everyday reasoning, even children who are raised in religious settings often initially understand God's mind as constrained and fallible, very similar to their understanding of ordinary human minds. Indeed, in their everyday reasoning, even adults who profess beliefs in God's extraordinary capacities tend to think of God as being subject to ordinary, human-like perceptual and mental constraints (Barrett \& Keil, 1996).

However, our results also speak to the important influence of sociocultural input, as indexed by religious exposure, in children's conceptual development and suggest that, with guidance, even quite young children can consider some agents' minds as less fallible. Four-year-olds in this religiously exposed sample, just as secularly schooled children in the earlier study (Lane et al., 2010), attributed accurate knowledge and beliefs to agents with exceptional perceptual abilities (e.g., Heroman), and, moreover, specifically referred to special perceptual abilities when justifying why these agents hold privileged information. As described earlier, this may be, in part, a product of children's exposure to media about certain agents' exceptional perception (e.g., Superman's X-ray vision) from a very early age.

More novel and intriguing, religiously exposed children in this study as young as 4 years evidenced an early appreciation for extraordinary mental abilities in their responses to Mr. Smart, an agent whose mental prowess they were first primed and then reminded about (Mr. Smart "knows everything"). This contrasts with the secularly schooled children studied by Lane et al. (2010) who received the same instructions and reminders about Mr. Smart. Thus, consistent exposure to ideas about the extraordinary mental and perceptual abilities of one agent-the Judeo-Christian God-may have facilitated children's understanding of Mr. Smart when children were specifically instructed and reminded he "knows everything." This occurred even though religious exposure had not yet resulted in children's spontaneous attribution of extraordinary mental capacities to God. Thus, at 4 years, an understanding that extraordinary agents can have extraordinary knowledge (know the contents of containers without perceiving those contents) had not yet reached a level of intuitive fluency. These data suggest that children's anthropomorphism strongly influenced their ability to apply the culturally/religiously provided information about "God" but that their ongoing religious instruction nonetheless facilitated their ability to apply information about extraordinary mental states when that information was directly and immediately provided. This could account for their relative sensitivity to information that we explicitly provided about Mr. Smart's extraordinary mind.

Notably, the difference between the religiously schooled children in this study and the secularly schooled children in a previous study (Lane et al., 2010) with respect to Mr. Smart (and even somewhat to God) was found for children in the middle age groups; that is, those children who were beginning to appreciate certain capacities and limitations of ordinary human minds. Indeed, among children who understood the fallible mental capacities of the girl and mom, children's knowledge of God predicted attributions of correct mental states to Heroman, Mr. Smart, and God. Thus, this period-when children are beginning to appreciate certain limits of human minds (e.g., the connection between seeing and knowing) - may also represent a period when children are particularly receptive to cultural input about extraordinary capacities 
that exceed those particular limits, and can begin to incorporate this information into their existing ToM.

In sum, the current study reveals that developing concepts of extraordinary perceptual and psychological abilities are a function of both children's conceptual architecture and the sociocultural input that children receive, and that conceptual change is not a simple product of the two. Importantly, the impact of sociocultural input on conceptual development varies depending upon children's existing conceptual structure (see also Evans, 2001). One way to describe the current results, therefore, is that sociocultural input is assimilated only to the extent that children's current conceptual structure-in this case, children's ToM-is able to integrate that input. Taken together with the data from Lane et al. (2010), we provide evidence that, although children may not be prepared to understand extraordinary mental capacities, at a certain point in ToM development (at around 4 years in this population), sociocultural input can facilitate an early appreciation for extraordinary minds. This would represent a developmental version of Sperber's (1996) reasoning about the "epidemiology of beliefs," with a focus on how "previously internalized cultural representations are a key factor in one's susceptibility to new representations" (p. 84). Children's developing understanding of ordinary minds makes them susceptible, at key junctures, to socioculturally provided information about extraordinary minds.

A next step in understanding children's concepts of extraordinary minds is to chart more specifically the intricate interplay between conceptual development and sociocultural input over the preschool and early elementary school years. Two lines of research seem particularly important for this endeavor. First, although we provide evidence that, with cultural assistance, children as young as 4 years can begin to appreciate the extraordinary capacities of some agents (e.g., knowing the contents of containers without looking inside); children at this age are not evidencing a full-fledged understanding of anything like omniscience. Omniscience refers to an agent's ability to know everything - not just the contents of boxes but also facts about the past and present, an ability to foretell the future, an ability to read minds, and much more. Arguably children's appreciation that some special agents can know contents of containers without seeing those contents marks the very beginning of a developing grasp of extraordinary mental abilities-the first of many steps involved in achieving an understanding of omniscience. Much as a developing understanding of ordinary minds proceeds through a series of developmental steps (Wellman \& Liu, 2004), so might a developing understanding of extraordinary minds. Future research should address when and how children come to appreciate that certain extraordinary agents (such as the Judeo-Christian God) can possess these other types of knowledge and how the progressive understanding of extraordinary mental capacities undergirds a remarkably counterintuitive understanding of total omniscience.

Second, as detailed in the current study and by Lane et al. (2010), some of these developmental transitions may last for only brief periods and are thus difficult to capture using cross-sectional data. Thus, a worthwhile next venture is to examine how these developments unfold longitudinally, using a microgenetic approach. Such work will shed further light on the precise development of supernatural concepts as children confront the limits of the human mind.

\section{References}

Atran, S., \& Sperber, D. (1991). Learning without teaching. In L. Tolchinsky-Landsmann (Ed.), Culture, schooling and psychological development (pp. 39-55). Norwood, NJ: Ablex.

Bamford, C., \& Lagattuta, K. H. (2010). A new look at children's understanding of mind and emotion: The case of prayer. Developmental Psychology, 46, 78-92.

Barrett, J. L., \& Keil, F. C. (1996). Conceptualizing a nonnatural entity: Anthropomorphism in God concepts. Cognitive Psychology, 31, 219-247.

Barrett, J. L., \& Richert, R. A. (2003). Anthropomorphism or preparedness? Exploring children's god concepts. Review of Religious Research, 44, 300-312.

Barrett, J. L., Richert, R. A., \& Driesenga, A. (2001). God's beliefs versus mother's: The development of nonhuman agent concepts. Child Development, 72, 50-65.

Bergstrom, B., Moehlmann, B., \& Boyer, P. (2006). Extending the testimony problem: Evaluating the truth, scope, and source of cultural information. Child Development, 77, 531-538.

Bering, J. M., Hernández Blasi, C., \& Bjorklund, D. F. (2005). The development of "afterlife" beliefs in religiously and secularly schooled children. British Journal of Developmental Psychology, 23, 587-607.

Boyer, P. (1996). What makes anthropomorphism natural: Intuitive ontology and cultural representations. Journal of the Royal Anthropological Institute, 2, 83-97.

Campbell, J. (1993). Myths to live by. New York: Penguin Group. (Original work published 1972) 
Carpendale, J. I. M., \& Lewis, C. (2004). Constructing an understanding of mind: The development of children's social understanding within social interaction. Behavioral and Brain Sciences, 27, 79-96.

Epley, N., Waytz, A., \& Cacioppo, J. T. (2007). On seeing human: A three-factor theory of anthropomorphism. Psychological Review, 114, 864-886.

Evans, E. M. (2001). Cognitive and contextual factors in the emergence of diverse belief systems: Creation versus evolution. Cognitive Psychology, 42, 217-266.

Evans, E. M., \& Wellman, H. M. (2006). A case of stunted development? Existential reasoning is contingent on a developing theory of mind. Behavioral and Brain Sciences, 29, 471-472.

Giménez-Dasí, M., Guerrero, S., \& Harris, P. L. (2005). Intimations of immortality and omniscience in early childhood. European Journal of Developmental Psychology, 2, 285-297.

Harris, P. L. (2006). Social cognition. In W. Damon, R. Lerner, D. Kuhn, \& R. Siegler (Eds.), Handbook of child psychology: Vol. 2: Cognition, perception, and language (6th ed., pp. 811-858). New York: Wiley.

Harris, P. L., \& Koenig, M. A. (2006). Trust in testimony: How children learn about science and religion. Child Development, 77, 505-524.

Knight, N., Sousa, P., Barrett, J. L., \& Atran, S. (2004). Children's attribution of beliefs to humans and God: Crosscultural evidence. Cognitive Science, 28, 117-126.

Lane, J. D., Wellman, H. M., \& Evans, E. M. (2010). Children's understanding of ordinary and extraordinary minds. Child Development, 81, 1475-1489.

Makris, N., \& Pnevmatikos, D. (2007). Children's understanding of human and super-natural minds. Cognitive Development, 22, 365-375.

Miller, S. A. (2009). Children's understanding of secondorder mental states. Psychological Bulletin, 135, 749-773.
Perner, J., Leekam, S. R., \& Wimmer, H. (1987). Threeyear olds' difficulty understanding false-belief: The case for a conceptual deficit. British Journal of Developmental Psychology, 5, 125-137.

Piaget, J. (1969). The child's conception of the world. Totowa, NJ: Littlefield, Adams. (Original work published 1929)

Pickover, C. A. (2001). The paradox of God and the science of omniscience. New York: Palgrave Macmillan.

Pratt, C., \& Bryant, P. (1990). Young children understand that looking leads to knowing (so long as they are looking into a single barrel). Child Development, 61, 973-982.

Repacholi, B. M., \& Gopnik, A. (1997). Early reasoning about desires: Evidence from 14- and 18-month-olds. Developmental Psychology, 33, 12-21.

Richert, R. A., \& Barrett, J. L. (2005). Do you see what I see? Young children's assumptions about God's perceptual abilities. International Journal for the Psychology of Religion, 15, 283-295.

Seeger, P., \& Gabrielsson, A. (1968). Applicability of the Cochran $\mathrm{Q}$ test and the $\mathrm{F}$ test for statistical analysis of dichotomous data for dependent samples. Psychological Bulletin, 69, 269-277.

Shtulman, A. (2008). Variation in the anthropomorphization of supernatural beings and its implications for cognitive theories of religion. Journal of Experimental Psychology: Learning, Memory, and Cognition, 34, 11231138.

Sperber, D. (1996). Explaining culture: A naturalistic approach. Oxford: Blackwell.

Wellman, H. M., \& Estes, D. (1986). Early understanding of mental entities: A reexamination of childhood realism. Child Development, 57, 910-923.

Wellman, H. M., \& Liu, D. (2004). Scaling of theoryof-mind tasks. Child Development, 75, 523-541. 


\section{Appendix: Agent Images and Introductions}

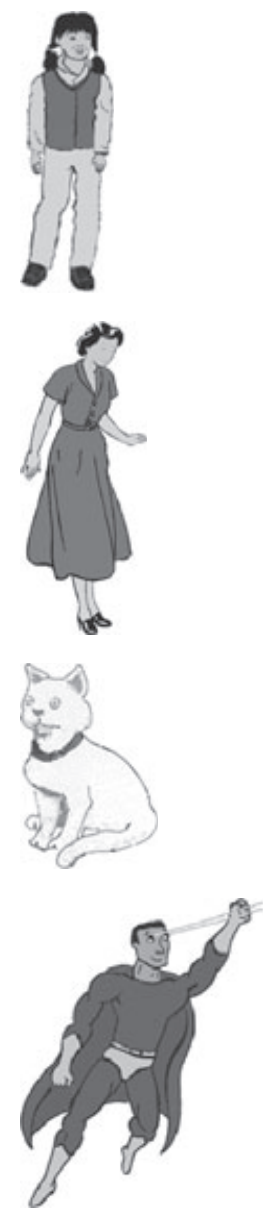

Girl

Let's talk about Mary. [Show picture of Mary]

Mom

Let's talk about your mom [show picture of mom]. It's not really a picture of your mom, but let's say it is.

Cat

This is a kitty cat [show picture of cat]. This kitty cat has special eyes that let him see in the dark.

\section{Heroman}

[Show picture of Heroman and say:]

This is Heroman. Heroman has super powers. He can fly very fast so that he can help lots of people all over the world. He also has eyes that let him see the insides of things, he can even see through walls.

[Show child a pen] Can you see this pen? [Place pen out-of-sight, behind paper] Now can you see the pen? [Place picture of Heroman on child's side of the paper] Well, Heroman can still see the pen. He can see through the paper and see the pen on the other side.

Remember, Heroman can fly very fast and can see right through things

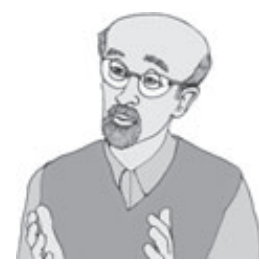

\section{Mr. Smart}

[Show picture of Mr. Smart, facing the child (away from the box) and say: ] This is Mr. Smart. Mr. Smart has special powers. He knows everything. [Show child closed opaque container that has a ball inside].

Do you know what's inside here? [Child responds: "No"].

Well, this is the first time that I've played with this, so I don't know what's inside either. Mr. Smart also hasn't played with this before. But because he's so smart he still knows what's inside. We would have to look inside, but he wouldn't even need to look. Mr. Smart, what do you think is in here? [Lean next to Mr. Smart]

Mr. Smart thinks that there is a ball inside. Let's see. [Open container and show child the ball]

Mr. Smart was right! Wow, he knows everything!

Remember, Mr. Smart is very smart. He knows everything. [Place Mr. Smart face-down, away from box]

God

Let's talk about God [show picture]. It's not really a picture of God, but let's say it is.

Note. Picture representing God (and language alluding to God's physical presence) was only presented to half of the sample. 